\title{
La construction d'une identité religieuse bouddhiste en Corée du Sud
}

Doctorat de sociologie, sous la direction de Danièle Hervieu-Léger, École des hautes études en sciences sociales (EHESS), soutenu le 9 décembre 2011.

Florence Galmiche

\section{(2) OpenEdition}

Édition électronique

URL : http://journals.openedition.org/assr/24579

DOI : $10.4000 /$ assr. 24579

ISSN : $1777-5825$

Éditeur

Éditions de l'EHESS

\section{Édition imprimée}

Date de publication : 30 décembre 2012

Pagination : 309-358

ISSN : 0335-5985

\section{Référence électronique}

Florence Galmiche, «La construction d'une identité religieuse bouddhiste en Corée du Sud », Archives de sciences sociales des religions [En ligne], 160 | octobre-décembre 2012, mis en ligne le 14 mars 2013, consulté le 22 avril 2019. URL : http://journals.openedition.org/assr/24579

Ce document a été généré automatiquement le 22 avril 2019

(c) Archives de sciences sociales des religions 


\section{La construction d'une identité religieuse bouddhiste en Corée du Sud}

Doctorat de sociologie, sous la direction de Danièle Hervieu-Léger, École des hautes études en sciences sociales (EHESS), soutenu le 9 décembre 2011.

\section{Florence Galmiche}

1 Après avoir été écarté du pouvoir, voire réprimé, pendant la dynastie dite confucéenne du royaume de Chosŏn (1392-1897), puis été mis en cause pour sa proximité avec le gouvernement colonial japonais (1910-1945), le bouddhisme est apparu extrêmement affaibli dans la société coréenne jusqu'aux années 1980. Depuis les années 1990 toutefois, il connaît un redéveloppement considérable ainsi qu'une profonde réorganisation, participant à la redéfinition du paysage religieux coréen.

Depuis le début du $\mathrm{xx}^{\mathrm{e}}$ siècle, le bouddhisme en Corée a été marqué par le croisement et parfois la confrontation de deux préoccupations majeures: sa modernisation et son intégration sociale d'une part, la refondation de sa légitimité monastique d'autre part. Cette thèse vise à comprendre la façon dont se reconstruit le bouddhisme dans la société sud-coréenne contemporaine, en particulier dans son appropriation des concepts de religion et de modernité, et comment il participe ainsi activement à leur redéfinition dans un contexte coréen. L'angle d'approche retenu est celui de l'analyse des divisions du travail religieux et notamment, la façon dont s'organisent les relations entre les laïcs et les religieux et dont interagissent, se confrontent et se définissent leurs identités respectives. Cette thèse s'appuie sur une méthodologie ethnographique combinant une observation participante dans différents monastères et des entretiens approfondis avec des bouddhistes laïcs, des moines et des moniales.

3 Le premier chapitre prend comme point de départ les prières pour la réussite aux examens d'entrée à l'université. Ce phénomène donne en effet lieu à une participation religieuse massive et suscite un fort investissement de la part des autorités religieuses pour encadrer et reformuler les pratiques dites populaires du bouddhisme et en 
particulier celles visant une efficacité directe. Puis, cette recherche analyse l'ambition partagée par les religieux et par les laïcs de construire et revendiquer une identité religieuse spécifiquement bouddhiste. Le deuxième chapitre poursuit cette réflexion en montrant comment de nouvelles formes de fréquentation du monastère sont favorisées et, à travers le développement et le renforcement d'associations de fidèles, comment se construisent une sociabilité, une identité et un réseau bouddhistes laïcs, visant notamment à renforcer le rôle et la place du bouddhisme dans l'espace public. Enfin, le dernier chapitre propose une échelle plus large et une perspective différente : il montre comment la dimension monastique et extra-mondaine, loin d'être éclipsée par les priorités d'intégration, d'utilité et de visibilité sociales des monastères urbains, est au contraire dotée d'une fonctionnalité nouvelle et constitue une dynamique centrale du renforcement du bouddhisme coréen, au travers notamment des interactions entre monastères de ville et de montagne et par la valorisation de la méditation de type Kanhwa Sŏn 看話樿.

4 Les manières d'étudier le bouddhisme coréen changent, mais, jusqu'à récemment, il a surtout été abordé sous l'angle de sa philosophie ou à partir de la vie et de la pensée de moines réputés. En accordant une attention particulière aux aspects concrets du religieux, à ses pratiques et modes d'organisation, cette recherche propose un point de vue nouveau sur plusieurs questions relativement classiques.

5 Premièrement, le fait d'avoir abordé le bouddhisme en effectuant d'intensives recherches de terrain parmi des laïcs a permis à la fois de préciser et de nuancer l'écart entre pratiques laïques et monastiques. Ce point de vue fait apparaître à la fois le fort engagement et le sérieux avec lesquels les fidèles souhaitent se rapprocher d'une forme d'orthodoxie et, en même temps, la marge de manœuvre et l'écart qu'ils s'autorisent par rapport à ces normes. Ceci doit être mis en lien avec une transformation importante du paysage religieux coréen dont cette thèse s'est fait l'écho: l'émergence d'une identité bouddhiste collective et revendiquée parmi les laïcs. Jusqu'au milieu ou la fin des années 1980, l'appartenance bouddhique concernait essentiellement les membres de la communauté monastique et quelques pieux laïcs, mais était relativement floue pour la majeure partie de la population fréquentant les cérémonies organisées dans les monastères. La revendication explicite $\mathrm{du}$ statut de fidèle (sindo) bouddhiste, généralement conditionnée par un engagement dans un parcours de formation religieuse et par une affiliation à un monastère et à l'organisation centrale, constitue un phénomène majeur. Cette manière nouvelle de se penser et de se présenter comme bouddhiste témoigne à la fois d'une réorganisation du bouddhisme et de la notion de religion dans la société coréenne et en Asie.

6 L'approche du bouddhisme en partant des laïcs permet également de mesurer à quel point la question de l'identité monastique ne peut être séparée de celle du laïc et inversement. Cette thèse présente en effet comment l'idéal monastique a été érigé en référence pour l'ensemble des pratiquants, remettant partiellement en cause la conception d'une différence radicale et d'une double éthique entre moines et laïcs. Elle donne cependant aussi à voir comment ce phénomène s'est accompagné d'une réaffirmation à la fois de la spécificité du moine et de son statut. Cette recherche montre finalement que, malgré des transformations profondes, certains aspects de la relation classique entre laïcs et communauté monastique - basée sur la circulation des dons et des mérites - sont demeurés centraux et même se sont renforcés. 
7 Enfin, en présentant l'interdépendance des monastères urbains et de montagne, cette thèse décrit comment le développement des monastères s'appuie précisément sur des mouvements en partie contradictoires. L'ébullition actuelle dans les milieux bouddhiques, visant à la fois à revivifier la dimension monastique de cette religion et à faire la preuve de sa pertinence et de son utilité sociale, donne lieu à des manifestations, des prises de position et des projets qui peuvent sembler à première vue paradoxaux. Par exemple, le monastère urbain sur lequel se concentrent en partie ces recherches se revendique " monastère de montagne ", avec toute la charge symbolique de renoncement et d'éloignement du monde que cela implique, tout en étant pleinement et activement intégré dans son environnement de grands ensembles, d'enseignes de cours particuliers et de boutiques luxueuses. Cette thèse propose une façon de comprendre cette juxtaposition de valeurs et de pratiques hétérogènes ainsi que la manière dont elle fait sens pour les personnes qui y participent. Les monastères urbains ne sont en aucun cas séparés du reste de la société, mais ils revendiquent comme aspect inhérent à leur identité une dimension de retrait et d'altérité par rapport à leur environnement. C'est en ce sens que certains se qualifient $d^{\prime}$ '« espaces de montagne au cœur de la ville » et cette résolution dialectique constitue l'un des ressorts de leur revendication d'utilité. Au-delà des monastères urbains et du bouddhisme coréen, il s'agit là d'une tension que l'on retrouve au cœur de la plupart des projets monastiques.

\section{AUTEUR}

\section{FLORENCE GALMICHE}

Florence.Galmiche@ehess.fr 